\title{
CHUVA, PRODUÇÃO DE SOJA E MÍDIA: A "REALIDADE" DESCRITA POR REPORTAGENS JORNALÍSTICAS VINCULADAS NA WEB
}

\author{
Vinicius Carmello ${ }^{(a)}$ \\ (a) Geógrafo, Doutorando e Bolsita Fapesp. Departamento de Geografia/Universidade Estadual Paulista - UNESP, \\ Presidente Prudente. \\ viniciuscarmello@gmail.com
}

Eixo: Climatologia em diferentes níveis escalares: mudanças e variabilidades

\begin{abstract}
Resumo
Um dos subsídios importantes utilizados em procedimentos metodológicos para estudos das repercussões climáticas no território são as reportagens vinculadas à mídia jornalística. Parte das pesquisas relacionadas a este tipo de investigação opta pela mídia jornalística impressa, por representar uma materialidade acessível a grande parte da população, entretanto neste trabalho optouse pela análise de noticias jornalísticas vinculada à mídia online, por se tratar de fontes informatizadas, e por vezes direcionadas a instituições e agentes tomadores de decisão. Foram coletadas reportagens jornalísticas que levassem em consideração três categorias diferentes: chuva intensa, ou excesso, estiagem/seca e chuva favorável. Notou-se que a "natureza" é colocada pela mídia como algo paralelo, longe de uma relação integrada com a história do homem, é atribuindo às chuvas o desenvolvimento de lavouras agrícolas com questionamentos acerca dos eventos meteorológicos que possa num determinado espaço, ocorrer.
\end{abstract}

Palavras chave: Mídia; chuva intensa; estiagem; seca; web jornalismo.

\section{1 . Introdução e revisão teórica}

Muitas são as noticias vinculadas diariamente na Internet que levam em consideração as necessidades climáticas por parte da cultura da soja. A maior importância se dá pelo fato da soja possuir, em diversas regiões do país, expressão econômica bastante considerável. Assim, dá-se grande atenção àquilo que se possa obstar o desenvolvimento desta cultura. As reportagens vinculadas à mídia online possuem grande expressividade na atual período técnico-científico. $\mathrm{O}$ acesso a este tipo de notícia se faz com maior rapidez e instantaneidade através dos produtos jornalísticos desenvolvidos para a web.

Tais abordagens ligam-se ao papel da mídia, considerada aqui como "objeto tecnológico capaz de transmitir a mesma informação para um vasto público ou massa. Esses objetos tecnológicos são os meios por intermédio dos quais a informação é transmitida ou comunicada" (CHAUI, 2006), e têm função de transmitir informação, entretenimento, opinião, publicidade e propaganda.

A mídia, através dos meios de comunicação de massa, é o principal motor para disseminação das informações. Estes meios têm atingido na sociedade atual uma ampla quantidade de pessoas, construindo 
reflexões diversas ou únicas sobre conteúdos ou fatos conforme seus interesses (NASCIMENTO JÚNIOR, 2012).

O jornalismo eletrônico, conforme é definido por Bastos (2000) pode ser considerado como uma pesquisa realizada em redes, onde as informações circulam em tempo real e cujo objetivo é a apuração jornalística (pesquisa de conteúdos recolha de informações e contato com fontes). Este autor utiliza o termo “jornalismo eletrônico" para englobar o jornalismo online e o jornalismo digital (MIELNICZUK, 2003). Tais termologias foram adotadas para os estudos aqui pretendidos.

O jornalismo digital também é denominado de jornalismo multimídia, pois implica na possibilidade da manipulação conjunta de dados digitalizados de diferentes naturezas (MIELNICZUK, 2003). Esta digitalização das informações recebe um suporte a mais quando se leva em consideração o desenvolvimento da técnica adaptada a estas funções, através de instrumentos sofisticados de som e imagem e softwares interativos para incrementar coletas jornalísticas. Para esta pesquisadora, o jornalismo online é desenvolvido utilizando tecnologias de transmissão de dados em rede e em tempo real.

Ressalta-se que, mesmo digitais, estas notícias jornalísticas podem manipular os dados e inverter histórias, transformando a realidade vivida (SOUZA, 2005). Entretanto, o que se pretende nesta fase da pesquisa é apenas refletir acerca destas cibernoticiais, observando e fundamentando aspectos importantes das análises do trabalho como um todo, mostrando o quanto tais problemáticas estão presentes no cotidiano contemporâneo da sociedade, sobretudo daqueles que do campo, sobrevivem.

\section{Procedimentos e técnicas}

Foram utilizadas 55 reportagens jornalísticas coletadas em jornais digitais. As buscas foram realizadas pelas palavras-chaves "estiagem + soja", ou "chuva + soja", inicialmente sem um recorte espacial específico, no sentido de se observar a influência das chuvas sobre o desenvolvimento da soja, principalmente no que se diz respeito aos prejuízos atribuídos àquelas mais intensas, a períodos de estiagem e as chuvas como fator favorável para o desenvolvimento da cultura. Para dividir as notícias jornalísticas, foram definidas três categorias diferentes: chuva intensa (ou excesso), estiagem/seca e chuva favorável.

A chuva intensa, ou excesso, estará, neste caso, associada àqueles episódios cuja chuva é considerada prejudicial em períodos de desenvolvimento da cultura da soja. No período de colheita dos grãos, o encharcamento das vagens secas, por exemplo, se torna inapropriado à colheita. Farias et al., (2009) coloca que a chuva intensa, ou excesso, vem acompanhado de episódios de precipitação de granizo, que 
danificam as plantas, ocasionando folhas estraçalhadas ou perfuradas, com perdas de área foliar e danos no caule. Em casos extremos, não existem medidas curativas a não ser a ressemeadura.

Conforme este autor, o excesso de chuvas resulta em plantas de baixa estatura, com folhas pequenas e amareladas. Além disso, o alagamento do solo, provocado por chuvas em excesso, pode prejudicar as atividades microbiológicas da planta com reflexos na qualidade e na produtividade final desta leguminosa.

A estiagem ou a seca entrará no que Ayoade (2001) expõe em relação aos azares climáticos na agricultura, sendo a seca constituinte de um grave risco a agricultura, tanto nas regiões temperadas quanto nas regiões tropicais. Para a sojicultura, dados mostram que as perdas, em razão da seca são constantes. Estiagem durante períodos específicos da cultura da soja causam reduções drásticas no rendimento de grãos (NEPOMUCENO, et al., 2009).

Já em relação às chuvas "favoráveis", optou-se por incluí-las a partir do momento que foi observado o quanto de importância é dada, pela mídia, a uma boa distribuição destas durante um ano agrícola, como forma de minimização, de reparo, de solução aos problemas de estiagem. Assim, criou-se uma categoria para encaixar as reportagens que trataram desta temática.

As reportagens foram contabilizadas e representadas conforme estes três segmentos e em seguida, foi realizada uma análise mais precisa do texto publicado nas reportagens jornalísticas, destacando trechos que deixam em evidência as questões pretendidas para cada grupo de notícias jornalísticas estudadas.

\section{Resultados e Discussão}

\subsection{As relações de "dependência” no discurso midiático}

Dentre as reportagens jornalísticas coletadas na web, 53\% das delas apresentaram conteúdo expressivo quanto a períodos de estiagens e seca durante o desenvolvimento da cultura da soja; $33 \%$ das noticias jornalísticas foram divulgadas demonstrando o quanto as chuvas podem ser determinantes e favoráveis ao desencadeamento das safras agrícolas e $14 \%$ das reportagens vinculadas à mídia virtual atribuíram às chuvas intensas os prejuízos junto ao rendimento e ao plantio da cultura da soja. Estes dados podem ser verificados no gráfico representado na Figura 1. 


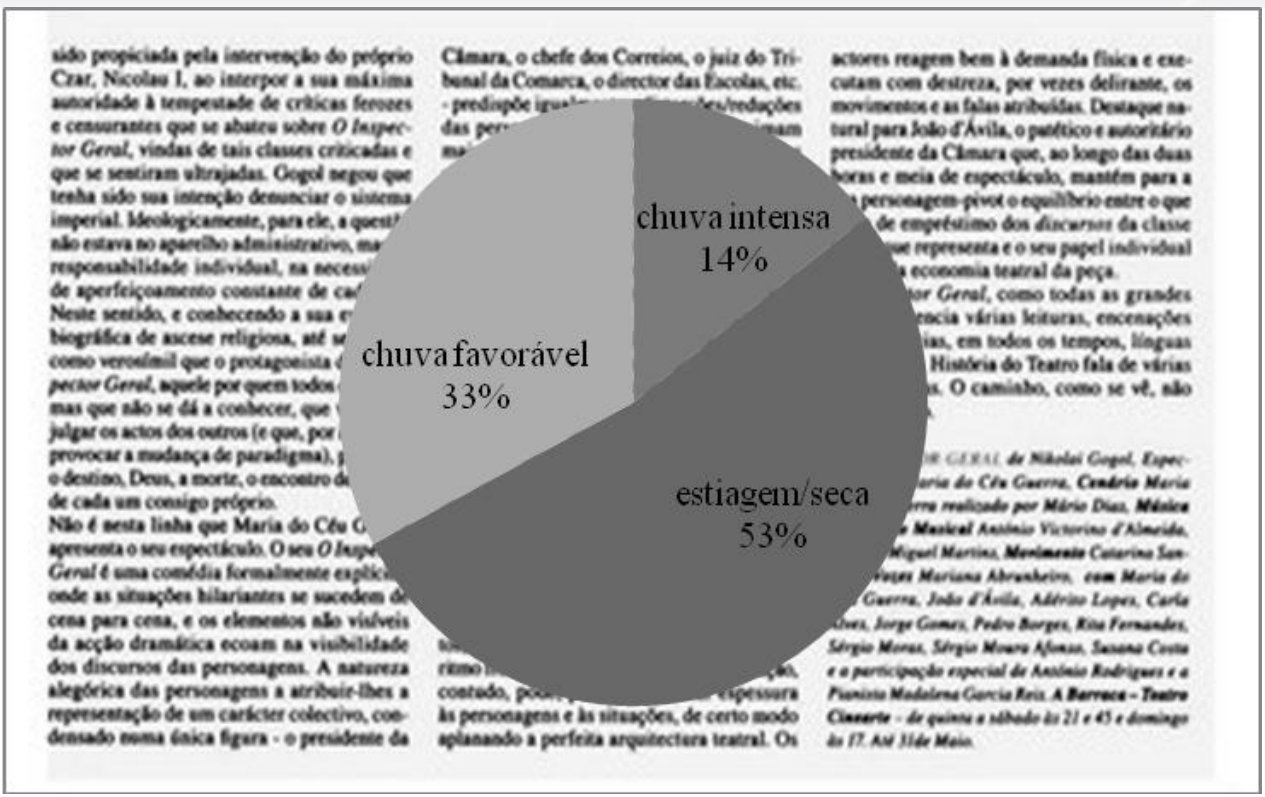

Figura 1: Quantificação das reportagens jornalísticas coletadas. Org.: Carmello (2012).

Dentre aquelas reportagens jornalísticas cujos objetivos foram de divulgar períodos de estiagem ou seca intensa em determinada área agricultável, nota-se que há grande ênfase na questão dos prejuízos e calamidades causadas por estes episódios. Por exemplo, na reportagem jornalística apresentada abaixo, Figura 2 a, um trecho traz a seguinte afirmação: “A falta de chuvas preocupa os agricultores, que em sua maioria praticam uma agricultura de subsistência. Em algumas localidades, ou mesmo regiões, os lavradores já começam a contabilizar os prejuízos".

Na Figura 2 b, outro trecho pode ser sublinhado como forma de exemplo: "Sua esperança é que o clima colabore e amenize os efeitos do La Niña na produção. Ele teme que a produtividade da oleaginosa caia de 58 sacas por hectare alcançados na safra passada para 33 saca/ha, como ocorre nas redondezas". Em ambos os exemplos há uma "ponte" entre a questão climática, a produção agrícola e a situação (tratada criticamente) do produtor rural. Ocorre um destaque para a questão da preocupação, da segurança e da esperança do produtor rural.

Em ambos os recortes, as reportagens são expostas numa dimensão analítico-descritiva, que segundo Carvalho (2002), relaciona-se a uma definição de problemas no intuito de descrever a realidade. A "natureza" é posta como "mentora" das transformações ocorridas nestes locais agrícolas. Sabe-se que ainda há grande influencia por parte do clima nas atividades agrícolas, ainda que muitos outros atributos 
possam estar relacionados com perdas e danos em safras agrícolas e que, por sua vez, deixam de ser expostos em reportagens jornalísticas que se enquadram apenas em descrever fatos ocorridos.

Falta de chuvas pode afetar a agricultura na região terça-feirs, 7 de fevereiro de 2012 11:00 am - 13 acessos
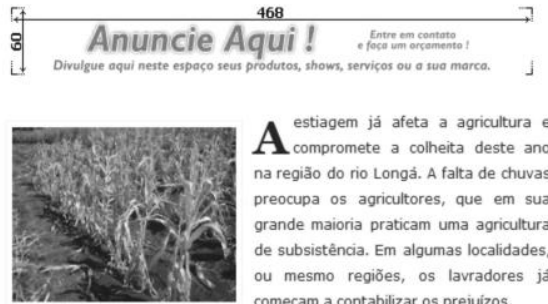

A estiagem já afeta a agricultura A compromete a collheita deste an na região do rio Longá. A falta de chuvas preocupa os agricultores, que em sua grande maioria praticam uma agricultura de subsistência. Em algumas localidades, ou mesmo regiões, os lavradores ja começam a contabilizar os prejuizos.

Com chuvas irregulares e abaixo do previsto, o governo do Estado teme uma "dura seca" no segundo semestre no Piauí, A previsão já foi comunicada ao governador Wilson Martins (PSB) que pediu providências das Secretarias de Defesa Civil e Desenvolvimento Rural. Se as chuvas não vierem à regiå̃o poderá ter perdas agricolas acima do esperado.

Além dos prejuizos que a falta de chuvas causará aos agricultores, muitos se reclama também do forte calor que assola no periodo da tarde, principalmente nas regiões mais secas. Meteorologistas da Secretaria Estadual de Meio Ambiente e Recursos Hidricos informaram à imprensa que a tendència é que as chuvas em 2012 fiquem dentro da média histórica.

Notícias $\square$ compartilhar $\square$ 흥 0

Soja semeada em outubro enfrenta altas temperaturas

07/02/12-00:00

Produtores do Paraná e Mato Grosso do Sul dependem da umidade para

amenizar perdas. Soja semeada em outubro enfrenta altas temperaturas

Nem tudo está perdido assim como nem todas as lavouras que receberam chuvas nas últimas semanas estão salvas. Produtores de regiões atingidas pelas estiagens de novembro e dezembro ainda dependem de umidade em Mato Grosso do Sul e no Paraná, apurou a Expedição Safra Gazeta do Povo durante visitas a diversas propriedades na última semana. Essas áreas foram semeadas em outubro e só devem ser colhidas a partir de março.

Com 270 hectares de cultivo, Emerson Penachiotti ainda tem soja verde em

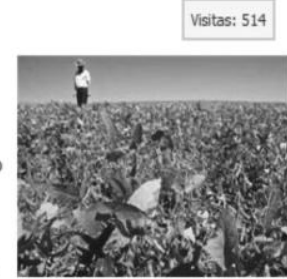
Floresta, Centro-Oeste do Paraná Do lado dessa lavoura existem áreas

com milho de inverno semeado. Sua esperança é que o clima colabore e amenize os efeitos do La Niña na produção. Ele teme que a produtividade da oleaginosa caia de 58 sacas por hectare alcançados na safra passada para $33 \mathrm{sc} / \mathrm{ha}$, como ocorre nas redondezas.

As plantações estão suportando temperaturas de até 35 graus, que esquentam o solo a mais de 50 graus. "No meu caso, a formação das plantas foi boa, mas não tem vagem. A soja deu árvore, mas jogou fora as flores", lamenta, temeroso diante de previsões que apontam apenas pancadas de chuva para a região.

No Sul de Mato Grosso do Sul, a região do estado mais atingida pela falta de umidade no início do plantio da soja, as plantas que ainda estão com os grãos em formação dão vantagem a José Sebastião Fernandes sobre seus vizinhos. Com 160 hectares, ele espera 55 sacas por hectare, enquanto produtores bem mais experientes prevêem dez sacas a menos.

Figura 2: À esquerda (a) reportagem jornalística retratando o problema da falta de chuva afetando a agricultura na região - Jornal Lesp (07/02/2012), À direita (b), reportagem jornalística divulgando o problema das altas temperaturas e da falta de chuva para a soja em Mato Grosso do Sul - Jornal Agro $(07 / 02 / 2012)$.

Nas reportagens jornalísticas seguintes, foram dadas maior atenção na questão da chuva quanto fator determinante e favorável para o desenvolvimento das lavouras de soja. No primeiro exemplo, Figura 3 a, é posto que: "muito aguardada pelos produtores rurais, a chuva que caiu em Santa Maria nos últimos dias amenizou os cenários das secas que assolaram os setores da agricultura e pecuária do município desde o início deste verão".

Conforme comentando nas reportagens subsequentes, este trecho descreve a realidade vivida pelos produtores rurais. Já o trecho seguinte está associado à outra forma de interpretação da realidade, induzindo o leitor a observar ações realizadas pelos órgãos locais no intuito de contornar influências do tempo atmosférico, conforme se observa: "as chuvas foram bastante comemoradas por nós e pelos agricultores, pois onde chove, renascem as plantas e renascem esperanças; A prefeitura está atenta. Estamos realizando obras e ações no interior para continuar ajudando e prevenindo eventuais problemas". 


$\begin{aligned} & \text { XVII Simpósio Brasileiro } \\ & \text { de Geografia Fisica Aplicada }\end{aligned}$
$\begin{aligned} & \text { I Congresso Nacional } \\ & \text { de Geografia Física }\end{aligned}$

Na reportagem jornalística seguinte, Figura 3 b, destaca-se o seguinte trecho: "as chuvas neste período são esperadas, favorecem as culturas que estão em pleno desenvolvimento e pastagens; o volume de água registrado em janeiro de 2012 já ultrapassou a precipitação acumulada no mesmo mês dos últimos dois anos". Nestes exemplos, observam-se intenções de dependência relacionadas às chuvas, porém, com um direcionamento em destacar-se ações visando contornar estas interferências, com construção de açudes e bebedouros visando menos dependência por parte dos fenômenos climáticos.

Neste ponto, ao observar os trechos realçados, é válido atribuir atenção ao que Fantazzini (2008) aponta sobre a mídia possuir profundas ligações com interesses políticos e econômicos. Por isso, os meios de comunicação não são apenas transmissores de informações, mas também fomentadores de crenças, culturas e valores destinados a sustentar os interesses econômicos e políticos que representam.

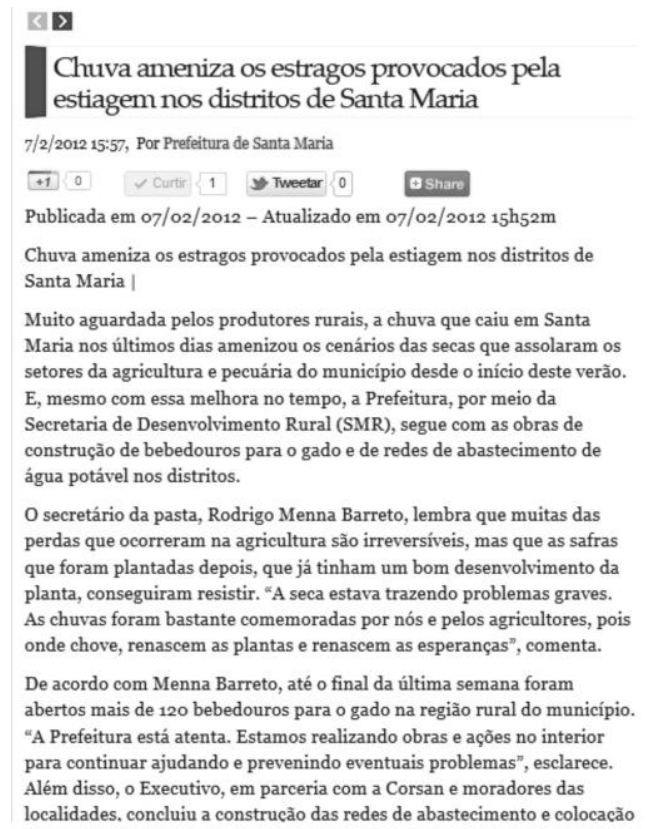

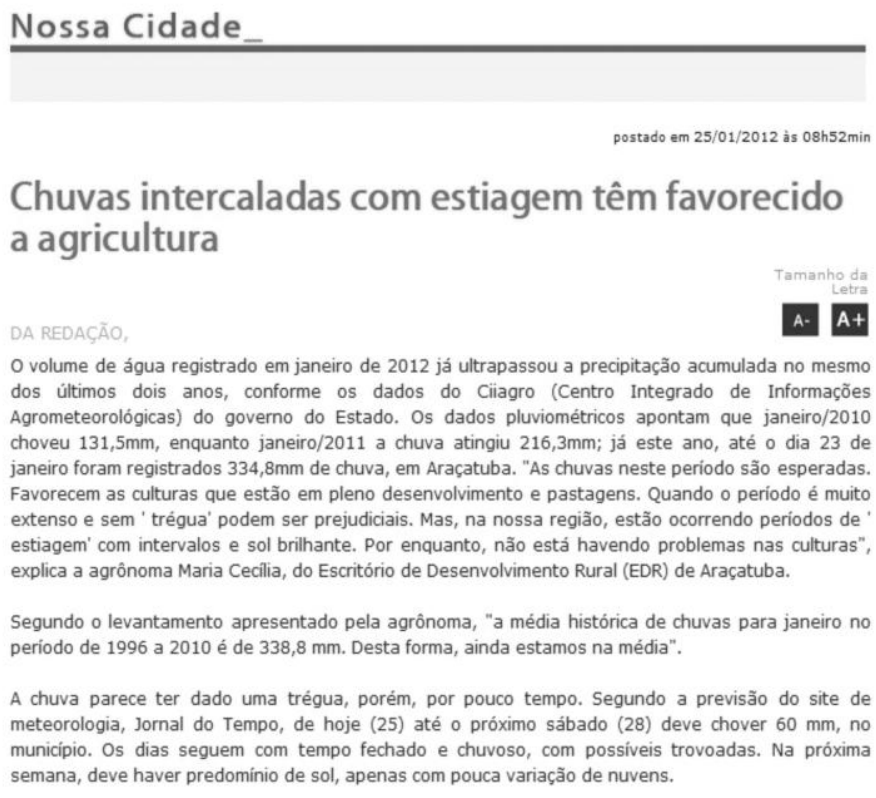

O volume de água registrado em janeiro de 2012 já ultrapassou a precipitação acumulada no mesmo dos últimos dois anos, conforme os dados do Ciiagro (Centro Integrado de Informações Agrometeorológicas) do governo do Estado. Os dados pluviométricos apontam que janeiro/2010 choveu $131,5 \mathrm{~mm}$, enquanto janeiro/2011 a chuva atingiu $216,3 \mathrm{~mm}$; já este ano, até o dia 23 de janeiro foram registrados $334,8 \mathrm{~mm}$ de chuva, em Araçatuba. "As chuvas neste periodo são esperadas. Favorecem as culturas que estão em pleno desenvolvimento e pastagens. Quando o período é muito extenso e sem ' trégua' podem ser prejudiciais. Mas, na nossa região, estão ocorrendo períodos de estiagem' com intervalos e sol brilhante. Por enquanto, não está havendo problemas nas culturas", explica a agrônoma Maria Cecilia, do Escritório de Desenvolvimento Rural (EDR) de Araçatuba.

Segundo o levantamento apresentado pela agrônoma, "a média histórica de chuvas para janeiro no periodo de 1996 a 2010 é de $338,8 \mathrm{~mm}$. Desta forma, ainda estamos na média".

A chuva parece ter dado uma trégua, porém, por pouco tempo. Segundo a previsão do site de meteorologia, Jornal do Tempo, de hoje (25) até o próximo sábado (28) deve chover $60 \mathrm{~mm}$, no município. Os dias seguem com tempo fechado e chuvoso, com possíveis trovoadas. Na próxima semana, deve haver predomínio de sol, apenas com pouca variação de nuvens.

Figura 3: À esquerda (a), reportagem levantando a questão da chuva como amenizadora dos estragos provocados pela estiagem em Santa Maria/RS - Correio do Brasil (07/02/2012). À direita (b), reportagem mostra a importância da chuva em favor da agricultura intercalada com períodos de estiagem - Nossa Cidade $(25 / 01 / 2012)$.

Dentre as 55 reportagens jornalísticas coletadas, oito foram aquelas que consideraram fatores relacionados a chuvas intensas capazes de desestabilizar o desenvolvimento da cultura da soja. Assim, ao prender-se em trechos específicos de cada reportagem, observa-se que a chuva nestes casos foi retratada como agente responsável pelos prejuízos ocorridos. Na Figura 3 a é exposto que: "depois de 26 dias de muita água na 
região, os produtores rurais contabilizam o prejuízo, que vai de $15 \%$ a $50 \%$ da área plantada em algumas fazendas; em outras, a colheita foi feita, mas a qualidade dos grãos ficou comprometida".

Este episódio de chuva intensa é posto como responsável direto dos prejuízos causados nas propriedades rurais descritas na reportagem. Entretanto, por mais que a reportagem tenha um papel descritivo, cabe ressaltar o quanto de responsabilidade é atribuído à chuva. Estas descrições aproximam-se das discussões acerca da produção social da natureza.

As chuvas, neste caso, determinam a dinâmica da sociedade e devem ser consideradas nas mais distintas áreas cuja sociedade se enquadra, não simplesmente pela sua importância, mas sim, como elemento "natural", presente e indissociável. Percebem-se por meio destas indagações os limites da técnica e principalmente da tecnologia desenvolvida para a agricultura na produção e na transformação da natureza.

Esta oposição entre sociedade e natureza configura-se em torno de cada cultura que cria um determinado conceito de natureza, já que, ao mesmo tempo em que cria e institui suas relações sociais, no interior destas relações sociais está embutida, portanto, uma determinada concepção de natureza (PORTOGONÇALVES, 2006). Esta insistência é observada nas relações entre natureza, determinada pela sociedade como "natural", representada neste trabalho pelas chuvas, e os sistemas agricultáveis, provenientes da ação do homem, dita social e, portanto, separada, como se houvesse uma alfândega proibindo sua interação.

Tais evidências podem ser observadas ao considerarem a chuva de forma isolada, atribuindo-a responsabilidades ao repercutirem no espaço geográfico, sobretudo quando estas estão associadas a impactos e prejuízos que, no caso da agricultura, vem caracterizada pelas reduções de safras.

Estas observações podem ser encontradas também na reportagem retratada na Figura 3 b. Nota-se maior ênfase na questão do episódio de chuva com granizo, causando, conforme descrito, grandes perdas aos agricultores da região. Assim, destacam-se os seguintes trechos: "a chuva de granizo de sábado afetou também algumas lavouras de soja e milho da região de Toledo. Como a maioria da soja está em estágio de desenvolvimento vegetativo, as folhas foram prejudicadas pelo forte impacto das pedras de gelo que vieram com o temporal". Assim como: "na lavoura do agricultor Nelson Cerutti, por exemplo, 40\% da área plantada de soja foram afetadas". 


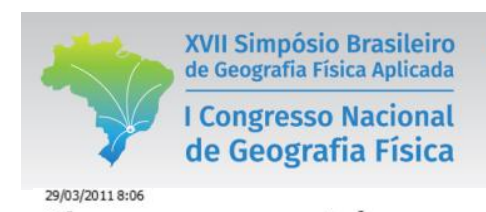

Chuvas geram prejuízo aos produtores de soja

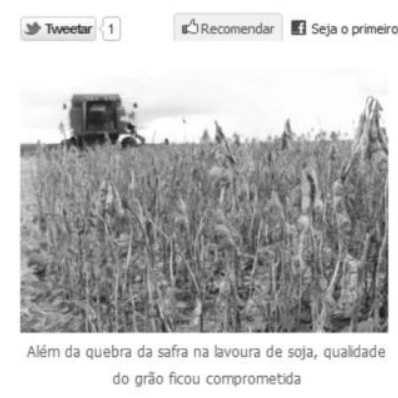

(167 mm) ficou dentro da média (199 mm).

De acordo com Leonardo Sologuren, consultor em agronegócio, as perdas no país podem chegar a 1 milhão de toneladas em relação às expectativas iniciais, até 72 milhões de toneladas. "Não podemos dizer que é a pior colheita dos últimos anos, mas gerou prejuź aos produtores. E essa perda depende de regão para regäo, variando de acordo com a quantidade e ciclo da soja plantada", afirmou. A consultoria não tem dados especficos do Triângulo Mineiro, somente do país.
OS DESAFIOS DA GEOGRAFIA FÍSICA NA FRONTEIRA DO CONHECIMENTO

Instituto de Geociências - Unicamp

Campinas - SP

28 de Junho à 02 de Julho de 2017

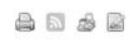

\section{Agricultores replantam soja perdida com o granizo}

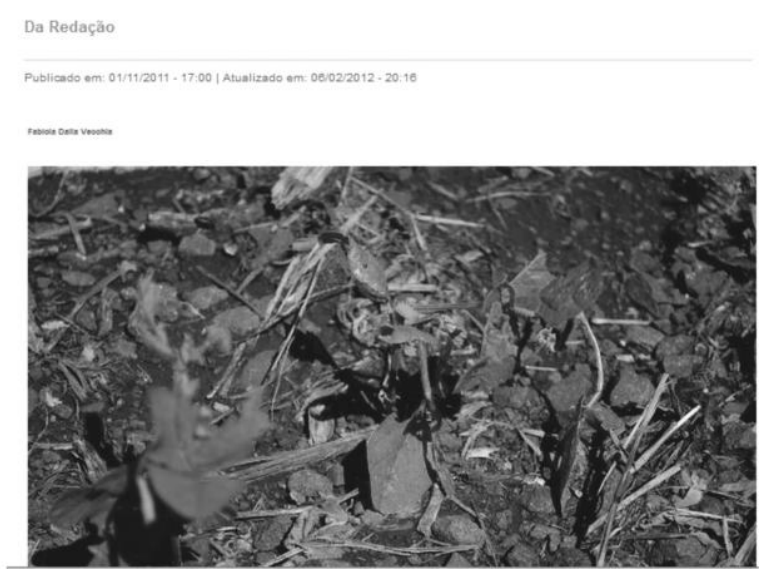

Figura 3: À esquerda (a), reportagem traz os prejuízos causados pelas chuvas intensas nos estados do Mato Grosso e Mato Grosso do Sul - Correio de Uberlândia (29/03/2011). À direita (b), reportagem expondo os prejuízos causados pelo granizo - Jornal do Oeste (01/11/2011).

\section{Conclusão}

O que não podemos deixar de ressaltar, para concluir este trabalho, é que a mídia é um espelho deformante, ou ainda, são vários espelhos deformantes que, cada um à sua maneira, mostra também um fragmento amplificado, simplificado e estereotipado do mundo (CHARAUDEAU, 2006). Assim, faz-se importante questionar a veracidade dos fatos descritos, por mais que estes se digam buscar tão somente narrar fatos ocorridos.

Nas reportagens analisadas neste artigo a natureza é colocada pela mídia como algo paralelo, longe de uma relação integrada com a história do homem. É atribuindo às chuvas, o desenvolvimento de lavouras agrícolas com questionamentos acerca dos eventos meteorológicos que possa num determinado espaço, ocorrer. Poucas foram as chances de se observar outras variáveis que por detrás, podem ser as grandes responsáveis pelos prejuízos dos agricultores, sendo, por exemplo, a falta de infraestrutura, financiamento agrícola, manejo adequado, políticas públicas e etc.

\section{Agradecimentos}

Agradeço à professora e colega Núbia Beray Armond pela leitura atenta e correção do artigo em 2012. 


\section{Bibliografia}

AYOADE, J. O. Introdução a Climatologia para os Trópicos. São Paulo: Ed. Bertrand. Brasil. 2001.

CARVALHO, A. Mudanças climáticas, organizações ambientais e impressa britânica. Universidade do Minho. Centro de Estudos de Comunicação e Sociedade. p. 1 - 24, .2002,

CHARADEAU, P. Discurso das mídias. São Paulo: Contexto, 2006.

CHAUİ, M. Simulacro e poder: Uma análise da mídia. São Paulo: Fundação Perseu Abramo, 2006

Correio do Brasil. Chuva ameniza os estragos provocados pela estiagem nos distritos de Santa Maria. Disponível em: http://correiodobrasil.com.br/chuva-ameniza-os-estragos-provocados-pela-estiagem-nos-distritos-de-santamaria/372832/. Acesso em: 07 fev. 2012.

Correio de Uberlândia. Chuvas geram prejuízo aos produtores de soja. Disponível em:

http://www.correiodeuberlandia.com.br/cidade-e-regiao/chuvas-geram-prejuizo-aos-produtores-de-soja/. Acesso em: 07 fev. 2012.

FARIAS, J. R. B.; NEPOMUCENO, A. L.; NEUMAIER, N. Soja. Agrometeorologia dos cultivos: o fator meteorológico na produção agrícola. Brasília: INMET, 2009.

Jornal Lesp. Falta de chuvas pode afetar a agricultura na região. Disponível em: http://jornalesp.com/2012/02/07/falta-de-chuvas-pode-afetar-a-agricultura-na-regiao/. Acesso em: 07 fev. 2012.

Jornal Agrolink. Soja semeada em outubro enfrenta altas temperaturas. Disponível em: http://www.agrolink.com.br/noticias/soja-semeada-em-outubro-enfrenta-altas-temperaturas_144031.html. Acesso em: 07 fev. 2012.

Jornal do Oeste. Agricultores replantam soja perdida com o granizo. Disponível em:

http://www.jornaldooeste.com.br/oeste-rural/noticias/11996/?noticia=agricultores-replantam-soja-perdida-com-ogranizo. Acesso em: 07 fev. 2012.

MIELNICZUK, Luciana. Jornalismo online e os espaços do leitor: um estudo e caso do NetEstado. (Dissertação de Mestrado). UFRGS/PPGCOM, Porto Alegre, 1998.

L. Sistematizando alguns conhecimentos sobre jornalismo na web. Não publicado.

NASCIMENTO JÚNIOR, L. A produção discursiva das mudanças climáticas. Geografia em Questão (Online), v. 7, p. 50-64, 2014.

Nossa Cidade. Chuvas intercaladas com estiagem têm favorecido a agricultura. Disponível em: http://www.lr1.com.br/index.php_pagina=noticia\&categoria=cidade\&noticia=28670. Acesso em: 25 jan. 2012.

PORTO-GONÇALVES, C. W. Os descaminhos do meio ambiente. 14 ed. 148 p. São Paulo: Contexto, 2006.

SOUZA, C. G. A influência do Ritmo climático na Morbidade respiratória em ambientes urbanos. (Dissertação de Mestrado). UNESP - Presidente Prudente, Presidente Prudente, 2007. 